Article

\title{
Acid-Base Flow Battery, Based on Reverse Electrodialysis with Bi-Polar Membranes: Stack Experiments
}

\author{
Jiabing Xia, Gerhart Eigenberger, Heinrich Strathmann and Ulrich Nieken * \\ Institute of Chemical Process Engineering, University of Stuttgart, Boeblinger Strasse 78, D-70199 Stuttgart, \\ Germany; icvt@icvt.uni-stuttgart.de (J.X.); gerhart.eigenberger@icvt.uni-stuttgart.de (G.E.); \\ heinrich.strathmann@icvt.uni-stuttgart.de (H.S.) \\ * Correspondence: ulrich.nieken@icvt.uni-stuttgart.de
}

Received: 19 November 2019; Accepted: 9 January 2020; Published: 11 January 2020

\begin{abstract}
Neutralization of acid and base to produce electricity in the process of reverse electrodialysis with bipolar membranes (REDBP) presents an interesting but until now fairly overlooked flow battery concept. Previously, we presented single-cell experiments, which explain the principle and discuss the potential of this process. In this contribution, we discuss experiments with REDBP stacks at lab scale, consisting of 5 to 20 repeating cell units. They demonstrate that the single-cell results can be extrapolated to respective stacks, although additional losses have to be considered. As in other flow battery stacks, losses by shunt currents through the parallel electrolyte feed/exit lines increases with the number of connected cell units, whereas the relative importance of electrode losses decreases with increasing cell number. Experimental results are presented with $1 \mathrm{~mole}^{-1}$ acid $(\mathrm{HCl})$ and base $(\mathrm{NaOH})$ for open circuit as well as for charge and discharge with up to $18 \mathrm{~mA} / \mathrm{cm}^{2}$ current density. Measures to further increase the efficiency of this novel flow battery concept are discussed.
\end{abstract}

Keywords: electrical energy storage; acid-base neutralization flow battery; reverse electrodialysis with bipolar membranes; stack test results

\section{Introduction}

The efficient storage and recovery of electrical energy is a key issue in the transition of electric energy generation from fossil fuels towards sustainable sources like solar and wind power. Flow batteries present an attractive solution, in particular for stationary and decentralized applications, since the amount of energy stored is separated from energy conversion. Presently, vanadium redox flow batteries are the most important and best-studied type of flow batteries. In redox flow batteries, the electric potential is generated by the electrochemical reactions at the electrodes.

As an alternative, the reverse electrodialysis (RED) has been proposed, where an electrical potential is generated across ion exchange membranes, which separate salt solutions of different ionic concentrations. In most cases studied, seawater and river water have been used as the two solutions [1]. Such a RED-stack consists of a sequence of cells containing one compartment for seawater and one for river water, separated by cation and anion exchange membranes. However, the open voltage of such a cell is only about $0.15 \mathrm{~V}$, which requires a large number of subsequent cells to obtain a reasonable stack voltage.

An interesting alternative RED-concept, which will be considered in the following, is based on the neutralization reaction of acid and base at the internal interface of a bipolar membrane, the reverse electrodialysis with bipolar membranes (REDBP). 
In [2] we presented an overview of previous publications on REDBP [3-5], together with our experimental result for a single REDBP cell unit, showing the potential advantages and discussing the present shortcomings of this-so far fairly overlooked-concept.

In the present contribution we extend our experimental results to REDBP stacks, consisting of 5 to 20 cell units. Figure 1 from [2] is a sketch of the stack under charge (lower half) and discharge conditions (upper half). Only one of several repeating cell units between the electrode chambers is shown and only the required main ionic fluxes and the electrode reactions are depicted.

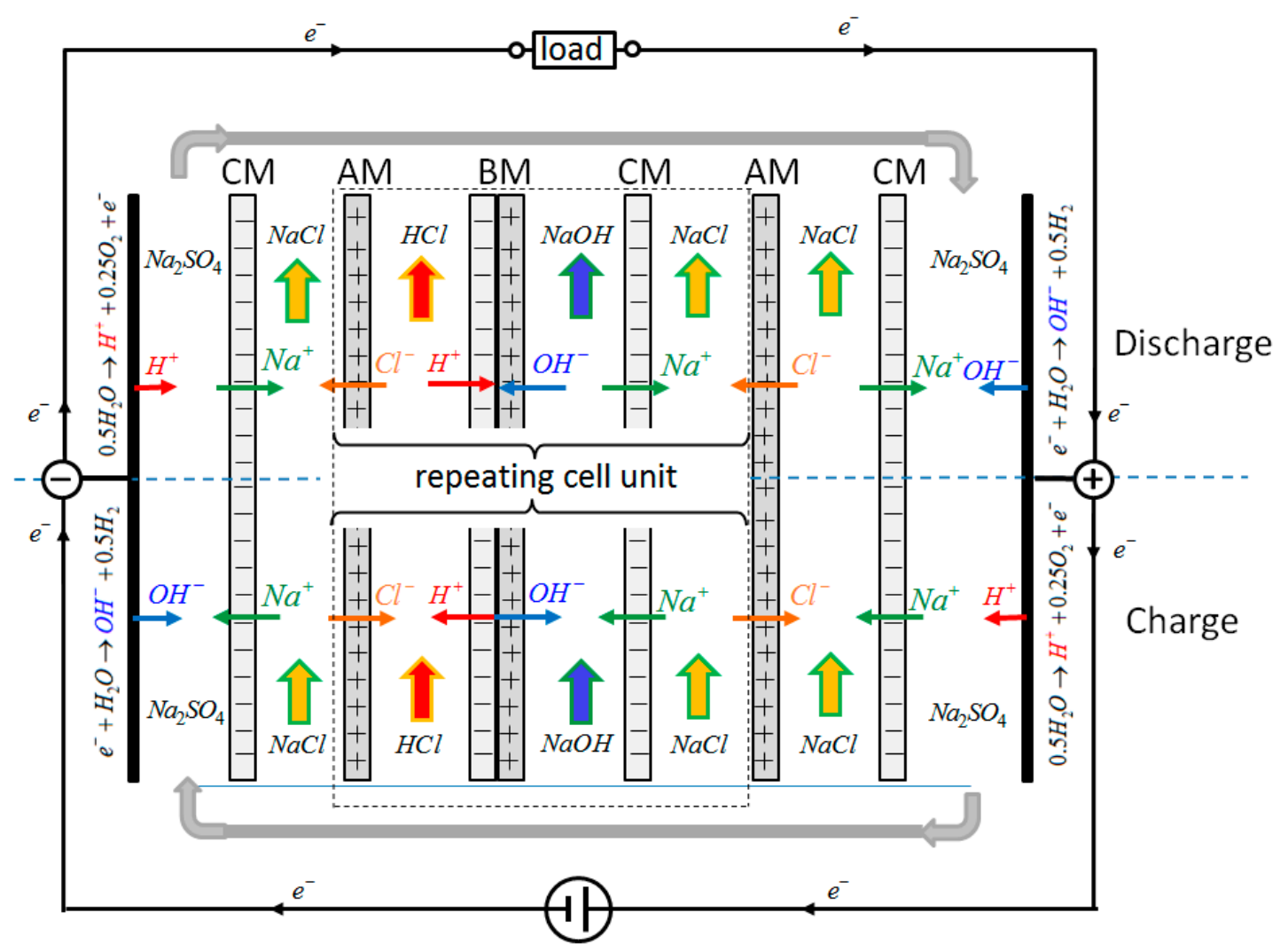

Figure 1. Schematic of main ionic fluxes and electrode reactions of the REDBP (reverse electrodialysis with bipolar membranes) stack used, in the lower part during charge and in the upper part during discharge. Only one of several repeating cell units is shown between the electrode compartments. The respective electrode reactions during charge and discharge are indicated at the electrodes. CM: cation exchange membrane, AM: anion exchange membrane, BM: bipolar membrane.

Each repeating cell unit consists of an acid $(\mathrm{HCl})$ and a base chamber $(\mathrm{NaOH})$ at both sides of the bipolar membrane $(\mathrm{BM})$. A salt compartment $(\mathrm{NaCl})$, separated from the acid or base chamber by an anion exchange membrane (AM) or a cation exchange membrane (CM), provides or accepts the respective $\mathrm{Cl}^{-}$and $\mathrm{Na}^{+}$ions to ensure electroneutrality. To form a REDBP stack, several repeating cell units have to be assembled, with an electrode compartment at each end of the stack.

The main element of each repeating cell unit is the bipolar membrane. Under charge (lower half of Figure 1), a sufficiently high electrical potential has to be applied over the electrodes such that water is split inside the bipolar membrane into $\mathrm{H}^{+}$and $\mathrm{OH}^{-} . \mathrm{H}^{+}$and $\mathrm{OH}^{-}$combine with $\mathrm{Cl}^{-}$and $\mathrm{Na}^{+}$from the adjacent salt chambers to produce $\mathrm{HCl}$ and $\mathrm{NaOH}$, which can be stored in separate storage tanks. This corresponds to the well-established process of acid and base generation from salt solutions by electrodialysis with bipolar membranes [6]. The respective electrode reactions are water splitting under generation of $\mathrm{OH}^{-}$and of $\mathrm{H}_{2}$ at the negative electrode and with $\mathrm{H}^{+}$and $\mathrm{O}_{2}$ generation at the positive electrode. The applied DC power supply transports electrons $\mathrm{e}^{-}$from the positive to the negative electrode. 
If the DC power supply is removed ("open circuit conditions") a potential will establish across each of the bipolar membranes in the stack. It prevents the further recombination of $\mathrm{H}^{+}$and $\mathrm{OH}^{-}$ inside each bipolar membrane. The sum of all resulting membrane potentials can be measured between the electrodes of the stack as open circuit voltage (OCV).

If the electrodes are connected via an external load (upper part of Figure 1) the unit can be used as a battery. Now $\mathrm{H}^{+}$from $\mathrm{HCl}$ and $\mathrm{OH}^{-}$from $\mathrm{NaOH}$ recombine to water inside each bipolar membrane and generate electric energy; the ionic fluxes in each repeating cell unit reverse. The resulting electric potential across all repeating cell units drives the depicted electrode reactions. The electrode reactions transform the ionic into electronic current, which flows through the load of the external circuit. The reaction details inside the bipolar membrane during charge and discharge have been discussed in [2]. They depend on the permselectivities and on the fixed charge densities of the ion exchange membranes used.

Commercially available membranes currently limit acid and base concentrations to $2 \mathrm{M}$, but long-term stability allows only for operation up to $1 \mathrm{M}$ [2]. Using $1 \mathrm{M}$ acid and base, the theoretical power density is $11 \mathrm{kWh} / \mathrm{m}^{3}$. Energy densities of vanadium redox flow batteries are in the order of $25 \mathrm{kWh} / \mathrm{m}^{3}$ [7].

\section{Experimental}

In our stack experiments hydrochloric acid $(\mathrm{HCl})$ and sodium hydroxide solutions $(\mathrm{NaOH})$ of different concentrations have been used as the respective acid and base, with 0.5 mole/ $\mathrm{L} \mathrm{NaCl}$ as the resulting salt solution. As shown in Figure 2, the respective solutions were circulated through the corresponding compartments from external storage tanks. Through the electrode compartments, a 0.25 mole/L sodium sulphate solution $\left(\mathrm{Na}_{2} \mathrm{SO}_{4}\right.$ was circulated instead of $\mathrm{NaCl}$, to avoid chlorine formation in the electrode reactions. In the set-up of Figure 1, tested in this contribution, an additional salt compartment $(\mathrm{NaCl})$ was placed between the sequence of repeating cell units and each electrode compartment, separated from the electrode compartments by a cation exchange membrane (CM). This should prevent the penetration of $\mathrm{Cl}^{-}$into the electrode compartments, which would lead to a release of $\mathrm{Cl}_{2}$ in the electrode reactions. Prime advantages of the chosen electrolytes are their low price, ample availability and low ecological concern.

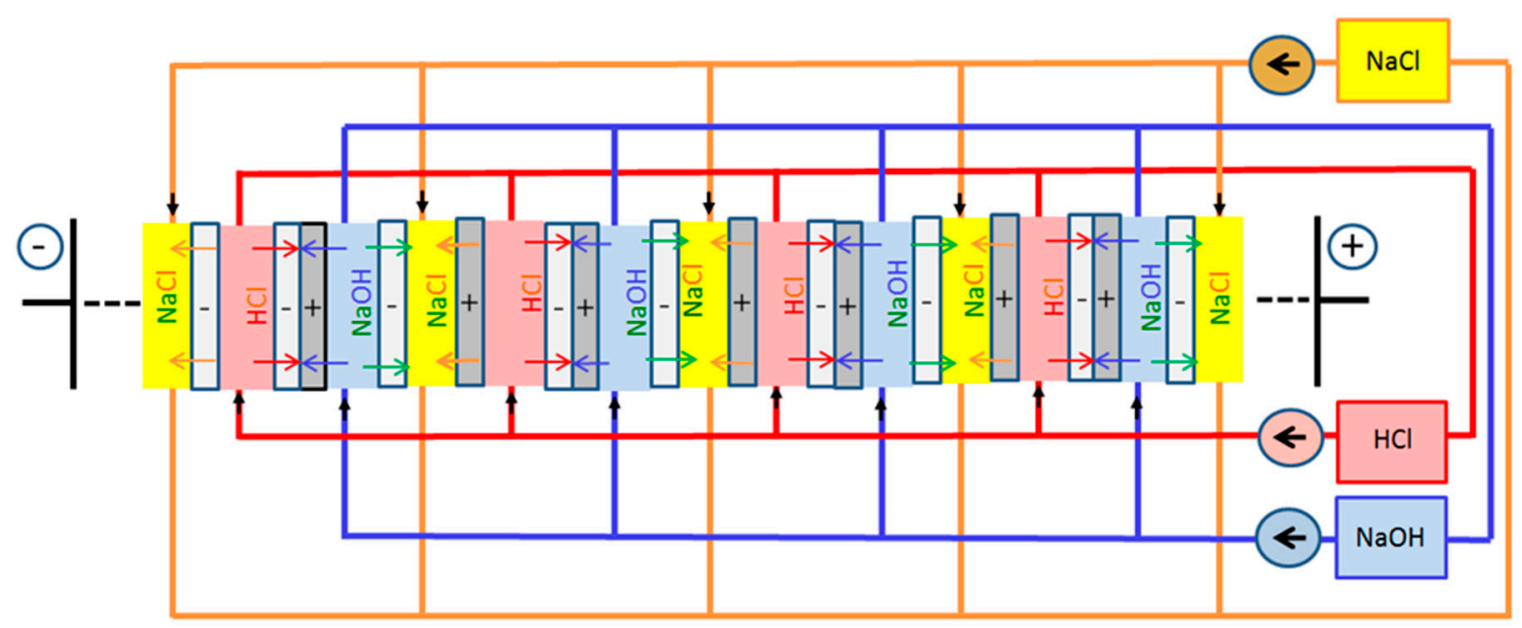

Figure 2. Parallel flow concept for acid, base and salt solution through four repeating cell units in the middle of a stack. The black arrows indicate the flow directions of acid $(\mathrm{HCl})$, of base $(\mathrm{NaOH})$ and of salt solution $(\mathrm{NaCl})$, and the colored arrows indicate the main fluxes of specific ions during discharge, also at OCV.

Table 1 shows the expected electrode reactions during charge and discharge. Their standard potentials represent a voltage sink of $1.23+0.83=2.06 \mathrm{~V}$, both at charge and at discharge. This loss 
could be reduced by modified electrode reactions with gas-consuming electrodes, but this was not in the scope of the present study.

Table 1. Electrode reactions during charge and discharge.

\begin{tabular}{cccc}
\hline & & Electrochemical Reaction & Standard Potential \\
\hline \multirow{2}{*}{ Discharge } & Left electrode (negative): Anode & $\frac{1}{2} \mathrm{H}_{2} \mathrm{O} \rightarrow \mathrm{H}^{+}+\frac{1}{4} \mathrm{O}_{2} \uparrow+e^{-}$ & $-1.229 \mathrm{~V}$ \\
& Right electrode (positive): Cathode & $e^{-}+\mathrm{H}_{2} \mathrm{O} \rightarrow \mathrm{OH}^{-}+\frac{1}{2} \mathrm{H}_{2} \uparrow$ & $+0.8277 \mathrm{~V}$ \\
\multirow{2}{*}{ Charge } & Left electrode (negative): Cathode & $e^{-}+\mathrm{H}_{2} \mathrm{O} \rightarrow \mathrm{OH}^{-}+\frac{1}{2} \mathrm{H}_{2} \uparrow$ & $-0.8277 \mathrm{~V}$ \\
& Right electrode (positive): Anode & $\frac{1}{2} \mathrm{H}_{2} \mathrm{O} \rightarrow \mathrm{H}^{+}+\frac{1}{4} \mathrm{O}_{2} \uparrow+e^{-}$ & $+1.229 \mathrm{~V}$ \\
\hline
\end{tabular}

Since the open circuit voltage (OCV) obtained in the single cell experiments with $1 \mathrm{M}$ acid and base was $0.76 \mathrm{~V}$, only a stack with three and more cell units would be able to compensate the electrode losses and deliver a net voltage during discharge. The influence of the electrode losses obviously decreases with an increasing number of cell units in the stack. However, the stack voltage is not fully proportional to the number of cell units. This is partly due to the so-called shunt currents, which flow through the feed and exit lines of the different electrolytes, transforming electrical energy into heat.

\subsection{Parallel Flow Concept}

In our set-up, a parallel flow concept for the electrolytes has been used, as shown schematically in Figure 2 for four repeating cell units in the middle of a stack. The parallel flow concept has the advantage of reduced pressure drop, compared to a serial flow concept where all of the acid, base and salt solution flows consecutively through adjacent cell units. The potential disadvantage is that the flow through adjacent parallel chambers may differ, if the flow resistances of the chambers are not equal. In addition, a parallel flow concept leads to larger ionic shunt currents through the feed/exit lines, as discussed in the next subsection. The colored arrows in Figure 2 indicate the main ionic fluxes across the membranes at discharge. At a smaller extent, similar fluxes also occur at OCV conditions. They are caused by a breakthrough of co-ions $\left(\mathrm{Cl}^{-}\right.$through $\mathrm{CM}$ and $\mathrm{H}^{+}$through AM), as discussed more detailed in [8]. This breakthrough is responsible for the fact that the open current voltage (OCV) across a repeating cell unit for $1 \mathrm{~mol} / \mathrm{L} \mathrm{HCl}$ and $\mathrm{NaOH}$ at $25{ }^{\circ} \mathrm{C}$ decreases from the theoretical value of $0.828 \mathrm{~V}$ to a measured value of $0.764 \mathrm{~V}$.

Like conventional electrodialysis stacks, the stack is formed from cell frames with pathways for the respective electrolytes, grid spacers in the cell frame windows, with the respective membranes and with rubber gaskets between cell frames and membranes. The cell frames for the stack experiments of $0.5 \mathrm{~mm}$ thickness have been obtained from DEUKUM Co, Frickenhausen, Germany (www.deukum.de), see Figure 3. They proved to be well suited for our lab-scale experiments, since they allow feeding of four different electrolytes through the holes in the frame. Their active membrane area is about $100 \mathrm{~cm}^{2}$. As for the single cell tests, the membranes (fumasep ${ }^{\circledR}$ FKB, fumasep ${ }^{\circledR}$ FAB and fumasep ${ }^{\circledR}$ FBM,) have been provided by Fumatech Co., Bietigheim-Bissingen, Germany. Their properties are listed in Table 2.

Table 2. Properties of membranes fumasep ${ }^{\circledR}$ FAB, fumasep ${ }^{\circledR}$ FBM with fumasep ${ }^{\circledR}$ PEEK as reinforcement, provided by Fumatech [9].

\begin{tabular}{ccccccc}
\hline Type & Reinforcement & $\begin{array}{c}\text { Thickness } \\
{[\mu \mathrm{m}]}\end{array}$ & $\begin{array}{c}\text { IEC } \\
{\left[\mathbf{m e q g}^{-1}\right]}\end{array}$ & $\begin{array}{c}\text { Selectivity } \\
{[\%]}\end{array}$ & $\begin{array}{c}\text { Specific Area } \\
\text { Resistance }\left[\boldsymbol{\Omega} / \mathbf{c m}^{2}\right]\end{array}$ \\
\hline FAB & anion & PEEK & $100-130$ & $1.0-1.1$. & $94-97$ & $4-7$ \\
FKB & cation & PEEK & $100-130$ & $1.2-1.3$ & $98-99$ & $4-6$ \\
FBM & bipolar & PEEK & $100-130$ & - & - & \\
\hline
\end{tabular}




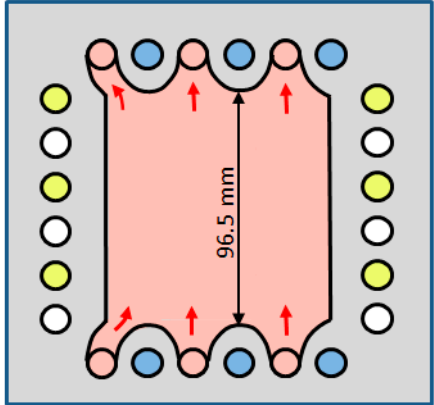

a)

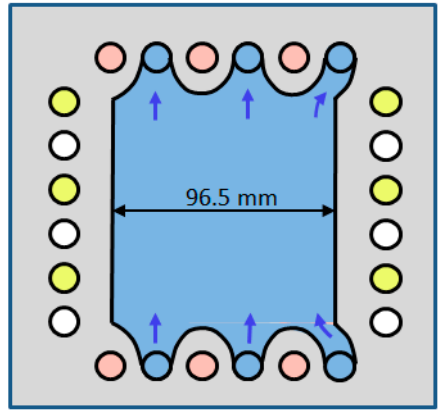

b)

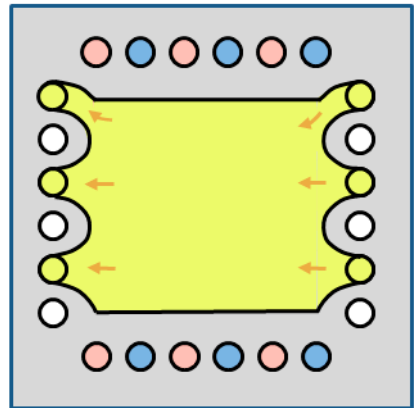

c)

Figure 3. Subsequent cell frames for one repeating cell unit: (a) for up-flow of $\mathrm{HCl}$, (b) for up-flow of $\mathrm{NaOH}$ and (c) for cross-flow of the $\mathrm{NaCl}$ solution.

Figure 3 shows the flow through subsequent cell frames, (a) for up-flow of $\mathrm{HCl}$, (b) for up-flow of $\mathrm{NaOH}$ and (c) for cross-flow of the $\mathrm{NaCl}$ solution. Together with the respective membranes, separated by rubber gaskets and grid spacers, the three frames form the repeating cell units shown schematically in Figure 1. The feed and exit flows of the respective electrolytes pass through the holes in the cell frames as indicated by the respective colors in Figure 3. All electrolytes are circulated by separate pumps from reservoirs through the respective compartments as indicated in Figure 2. Further details of the design are given in [8].

\subsection{Voltage Measurements}

The most direct information during stack operation can be obtained from voltage measurements along the stack. In the single repeating cell unit studied in [2], Haber-Luggin capillaries with calomel electrodes have been used to measure the voltage drop across the respective membranes. To reduce the ample space required for the Haber-Luggin capillaries, in the present stack experiments the voltages between different repeating cell units have been measured by thin $\mathrm{Pt}$ wires. The insulated $\mathrm{Pt}$ wires were introduced and sealed between two rubber gaskets. To minimize concentration effects, the $\mathrm{Pt}$ wires were only positioned in the acid compartments, where ionic conductivities are high and about equal throughout the stack.

In the following, voltage measurements will be presented where Pt wire probes were positioned in the center of the 1st, the 2nd, the 6th, the 11th and the 19th acid cell of the stack. This allows measurement of the voltages across the 1st repeating cell unit, across the first five-cell unit (next to the electrode) and across the second five-cell unit (in the middle of the stack). In order to determine the total voltage of the 20-cell stack, the measured first cell voltage was added to the voltage measured between the first and the 19th acid compartment, assuming that the voltage across the repeating cell units next to both electrodes was equal.

\subsection{Operating Conditions}

In all cases, $\mathrm{Na}_{2} \mathrm{SO}_{4}$ electrolyte of $0.25 \mathrm{M}$ was circulated through the electrode chambers and $0.5 \mathrm{M}$ $\mathrm{NaCl}$ electrolyte was circulated through the salt chambers, while the concentration of $\mathrm{HCl}$ and $\mathrm{NaOH}$, circulated through their chambers, was varied between $0.5 \mathrm{M}$ and $1 \mathrm{M}$. If not specified differently, the empty-space flow velocity through the electrolyte chambers was adjusted to a mean value of about 2 to $3 \mathrm{~cm} / \mathrm{s}$.

\section{Results and Discussion}

In this section, the measured voltages in stacks consisting of 5 to 20 repeating cell units are presented and discussed for different acid and base concentrations, for different charge and discharge currents and for different charge/discharge periods. 


\subsection{Open Circuit Voltage (OCV)}

With the Pt wire probes, the open circuit voltage can be measured between different cell units as mentioned above, but OCV for the whole stack can also be measured directly between the electrodes of the stack. Table 3 presents OCV results for increasing stack size between 1 and 20 repeating cell units if the electrolytes flow through the stack continuously (constant ion concentrations). In an ideal stack, OCV should amount to the theoretical single cell voltage $\left(0.828 \mathrm{~V}\right.$ for $1 \mathrm{M}$ acid and base at $\left.25^{\circ} \mathrm{C}\right)$ times the number of repeating cell units. With the measured single cell voltage of $0.764 \mathrm{~V}$, the theoretical values of the stack are given in the second row. The actually obtained OCV values, measured across the electrodes, are given in the third row. While the measured values are still close to the calculated values for up to 10 repeating cell units, an increasing voltage loss is observed if the cell unit number is raised to 15 and further to 20 cells. Reasons for this trend are discussed in the next section.

Table 3. Calculated and measured open circuit voltage (OCV) for $1 \mathrm{M}$ acid and base at $25^{\circ} \mathrm{C}$, depending on the number of repeating cell units.

\begin{tabular}{cccccc}
\hline Number of Repeating Cell Units & $\mathbf{1}$ & $\mathbf{5}$ & $\mathbf{1 0}$ & $\mathbf{1 5}$ & $\mathbf{2 0}$ \\
\hline OCV calculated from single cell voltage & $0.764 \mathrm{~V}$ & $3.82 \mathrm{~V}$ & $7.64 \mathrm{~V}$ & $11.46 \mathrm{~V}$ & $15.28 \mathrm{~V}$ \\
OCV measured across electrodes & $0.764 \mathrm{~V}$ & $3.8 \mathrm{~V}$ & $7.6 \mathrm{~V}$ & $11.2 \mathrm{~V}$ & $14.4 \mathrm{~V}$ \\
\hline
\end{tabular}

\subsection{Self-Discharge at $\mathrm{OCV}$}

The experimental results of Table 2 have been obtained with stacks where the required electrolytes were continuously pumped through the stack, compensating the effect of any side reactions or shortcuts, which may consume acid and base at OCV. In the OCV experiments reported in Figure 4, the electrolyte flows have been stopped at the beginning of the experiment. Now the resulting drop of the voltage in stacks with different numbers of repeating cell units can be analyzed over time. This should provide indications as to why OCV across stacks with a larger number of repeating cell units increases less than proportional to the number of units, as shown in Table 2. A self-discharge due to limited membrane permselectivities, as indicated by the ionic flux arrows at OCV in Figure 2 and discussed in detail in [2], could contribute to the effect. However, it should not be responsible for the less than proportional increase of OCV with the number of repeating cell units.

Figure 4a-d show the results of the self-discharging tests of (a) 5-cell, (b) 10-cell, (c) 15-cell and (d) 20-cell stacks with initial $1 \mathrm{M}$ acid and base. In a 5-cell stack (Figure 4a), the self-discharge is very low, and OCV remains close to $4 \mathrm{~V}$ during the whole measurement period. In a 10-cell stack (Figure $4 \mathrm{~b}$ ), the stack voltage is about doubled and a slow self-discharge is followed by an accelerated discharge after about $30 \mathrm{~min}$ down to a level of $4 \mathrm{~V}$. If the cell number is further increased (Figure $4 \mathrm{c}, \mathrm{d}$ ), the accelerated drop from the higher stack voltage down to about $4 \mathrm{~V}$ occurs at about $20 \mathrm{~min}$ for the 15-cell stack, and at about 12 min for the 20-cell stack. This faster decrease of OCV is consistent with the assumption that ionic shunt current through the feed/exit lines of the electrolytes should be responsible for the OCV decrease. A similar influence of shunt currents through parallel feed/exit lines of the electrolytes is well known from redox flow batteries [10-12]. 

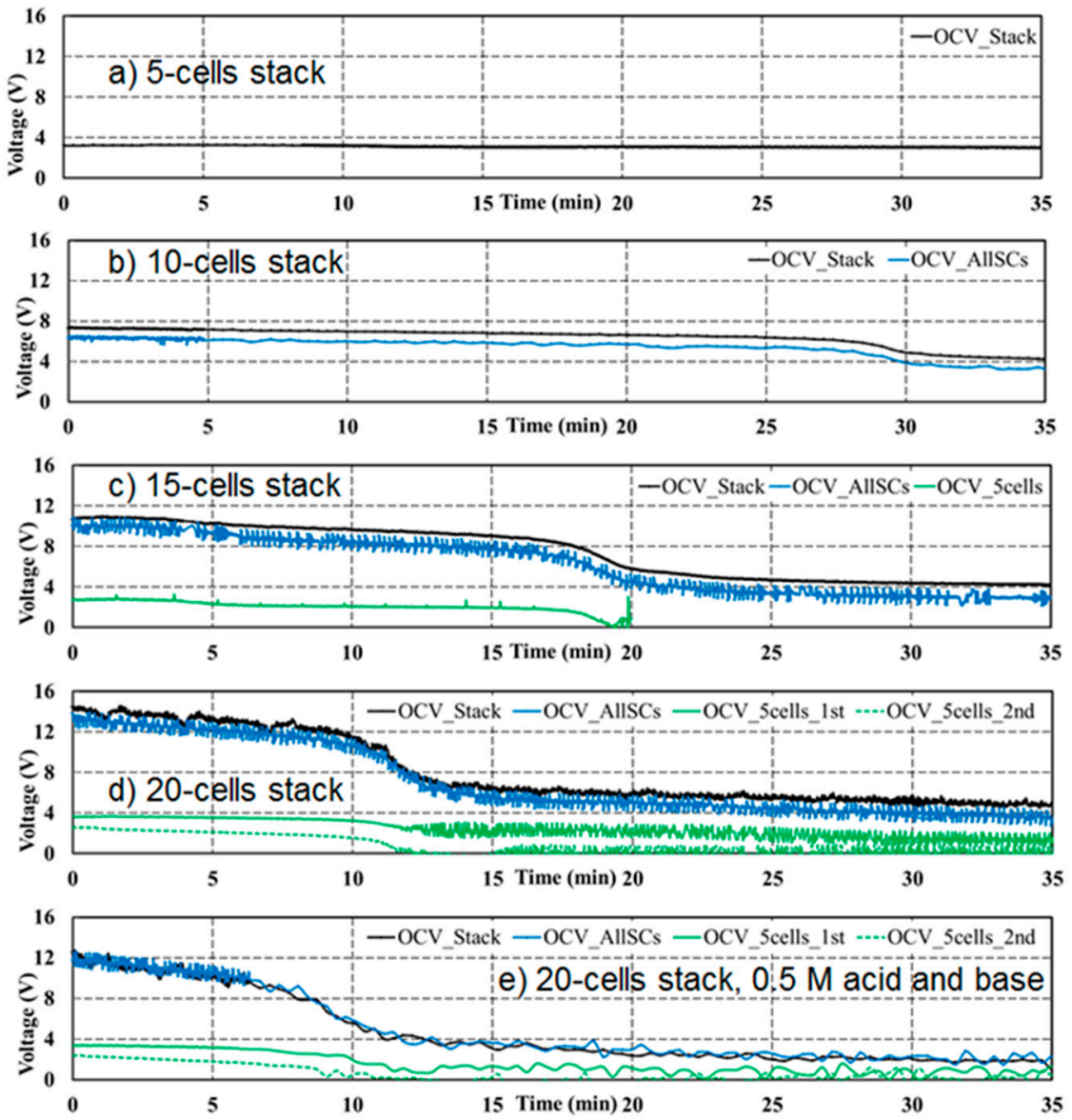

Figure 4. Self-discharge test at $25^{\circ} \mathrm{C}$ for different stack sizes and different acid and base concentrations. (a) 5-cell stack, $1 \mathrm{M}$ acid and base, (b) 10-cell stack, $1 \mathrm{M}$ acid and base, (c) 15-cell stack, $1 \mathrm{M}$ acid and base, (d) 20-cell stack, $1 \mathrm{M}$ acid and base, (e) 20-cell stack with $0.5 \mathrm{M}$ acid/base concentration. OCV_Stack (black) has been measured between the electrodes, OCV_AllSCs (blue) between the first and the last repeating cell unit of the stack, OCV_5cells_1st (green solid) and OCV_5cells_2nd (green, dotted) have been measured across the first and second 5-cell unit.

In stacks with 10 and more cells, OCV shows an accelerated decline to about $4 \mathrm{~V}$ after a certain period of low decline, which becomes shorter with increasing cell number. An explanation can be drawn from Figure 4d. Here, the difference between OCV over the first 5 cells of the stack (OCV_5cells_1st, green solid line) and OCV over the second 5-cell package (OCV_5cells_2nd, green dotted line) is shown. The voltage over the 5 middle cells was smaller than that over the first 5 cells from the very beginning. It dropped to (almost) zero at the time of the accelerated decline of the total cell voltage, whereas the voltage over the first 5 cells was less affected. The voltage decline indicates that the acid and base have been completely consumed (neutralized) in the middle of the stack, but are still present in the cells next to the electrodes. This can be explained by the ionic shunt currents through the feed/exit lines of the electrolytes. Since $\mathrm{H}^{+}$and $\mathrm{OH}^{-}$have much higher ionic mobility than the other ions present, only the influence of $\mathrm{H}^{+}$and $\mathrm{OH}^{-}$shunt currents in the acid and base feed/exit lines will be considered in the following, using the simplified picture in Figure 5. 
a)

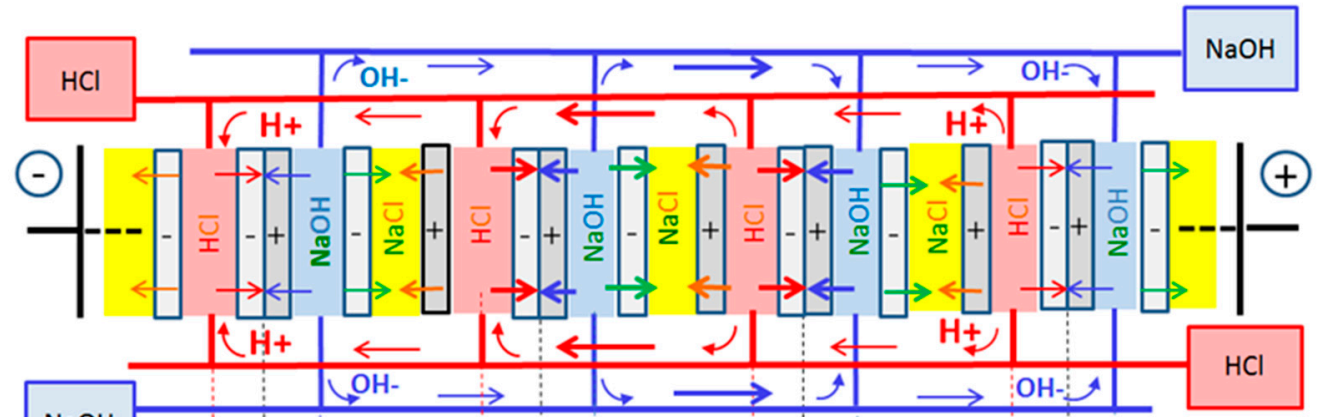

b)

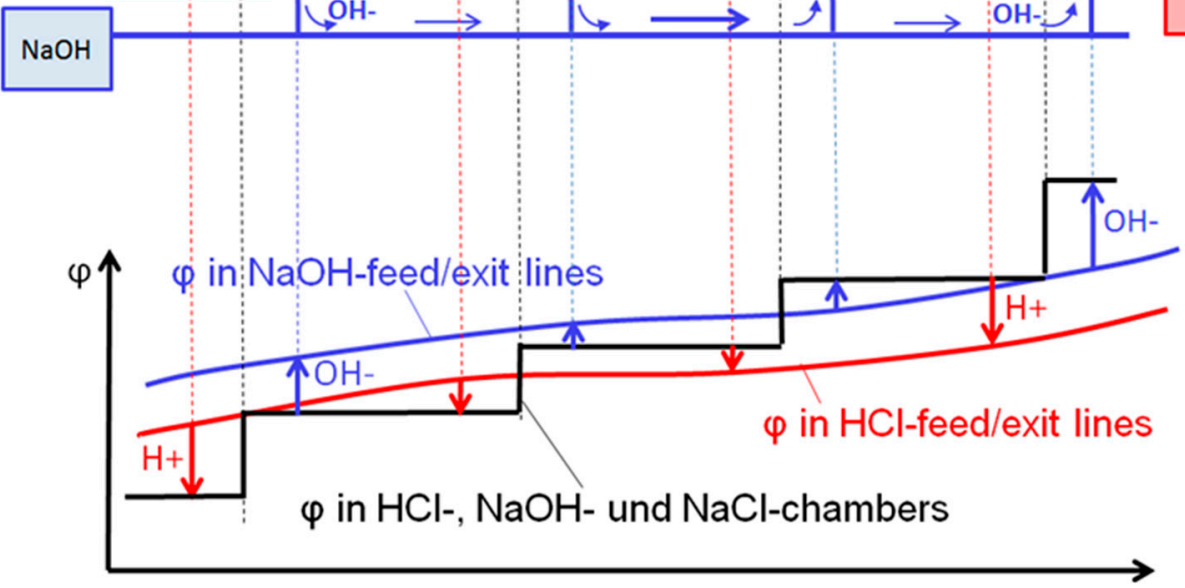

Figure 5. (a) Simplified sketch of ionic shunt currents of $\mathrm{H}^{+}$(red arrows) and $\mathrm{OH}^{-}$(blue arrows) through the feed/exit lines of acid and base, and compensating ionic currents inside of four repeating cell units in the middle of the stack. The different arrow thickness indicates the increased shunt currents in the stack center. (b) Corresponding electric potential profiles $\varphi$ across the repeating cell units (black) and in the acid (red) and the base feed/exit lines (blue). The arrows indicate the direction of the ion fluxes between cell compartments and feed/exit lines.

In Figure 5a only four repeating cell units in the middle of the stack are shown, together with their feed/exit lines for acid (red) and base (blue). At OCV, a voltage profile $\varphi$ (black) develops across the stack as shown in Figure 5b. It mainly consists of the voltage steps in each of the bipolar membranes. The voltage gradient across the stack causes a counter-movement of $\mathrm{H}^{+}$ions and $\mathrm{of}^{-}$ions along their feed/exit lines as indicated by the red and blue arrows in Figure 5a. The ions originate from the acid/base compartments at one side of the stack and turn back into the respective compartments at the opposite side. This leads to an ion flux maximum in the stack center. To ensure electroneutrality, the ion fluxes through the feed/exit lines have to be compensated by fluxes of opposite direction through the cell compartments. This leads to the indicated fluxes with neutralization of $\mathrm{H}^{+}$and $\mathrm{OH}^{-}$inside the bipolar membranes, which is maximal in the middle of the stack. Comparable to a simple mixing of acid and base, this neutralization energy is converted into heat, representing a self-discharge with loss of electrical energy. The fluxes of $\mathrm{H}^{+}$and $\mathrm{OH}^{-}$into the bipolar membranes have to be compensated by equivalent fluxes of $\mathrm{Cl}^{-}$and $\mathrm{Na}^{+}$into the adjacent salt compartments.

Arrows in Figure 5b qualitatively depict the driving potentials between the feed/exit lines and the potentials on both sides of the respective bipolar membranes. This explains why the ion fluxes of $\mathrm{H}^{+}$and $\mathrm{OH}^{-}$between the stack cells and the feed/exit lines change direction in the middle of the stack, as indicated by the arrows in Figure 5a,b. The fluxes of $\mathrm{H}^{+}$and $\mathrm{OH}^{-}$through the feed/exit lines accumulate in the stack center as indicated by the arrow thickness. The compensating fluxes inside the repeating cell units are therefore also strongest in the middle of the stack. This leads to the pronounced self-discharge and the resulting drop of OCV across the bipolar membranes in the middle of the stack.

In summary, the ionic shunt currents of $\mathrm{H}^{+}$and $\mathrm{OH}^{-}$ions in the acid/base feed exit lines are driven by the potential along the acid/base feed/exit lines and result in a neutralization reaction in the bipolar membranes. Estimation shows that in the stack used, shunt currents due to $\mathrm{H}^{+}$migration through the 
feed/exit lines of $\mathrm{HCl}$ amount to more than $60 \%$ and due to $\mathrm{OH}^{-}$migration through the feed/exit lines, $\mathrm{NaOH}$ amounts to more than $30 \%$ of the total shunt current [8]. This leads to the consumption of acid and base, primarily in the stack center, which reduces the respective cell voltages. If under OCV the flow of acid and base is stopped, it leads to the gradual neutralization of all acid and base in the stack center as can be concluded from the voltage drop to zero of "OCV_5cells_2nd" after about 12 min in Figure $4 d$.

In Figure 4e, results are presented where the initial acid/base concentration has been reduced from 1 to $0.5 \mathrm{M}$. This reduction of $50 \%$ should result in an accelerated discharge in about half the time. However, since the reduced concentrations also lead to reduced ionic conductivities and hence to a reduced shunt current, only a small difference between Figure 4 d,e can be observed. Again, OCV across the second 5-cell unit in the stack center drops to zero, now after around $10 \mathrm{~min}$.

The above details of the observed OCV decline after stopping the acid/base feed help to elucidate the influence of shunt currents. However, it should be mentioned that shunt currents are only of importance for the REDBP battery during operation. The consumption of acid and base by self-discharge at OCV is limited to the amount present in the stack and does not affect the concentration of acid and base in the storage tanks. This is a general advantage of flow batteries.

To determine all the details of ionic flux interactions, a numerical simulation of the whole stack would be required, where ionic species balances for all ionic species as well as electroneutrality have to be enforced in the whole stack. But this is out of scope for the present contribution.

\subsection{Charge and Discharge Behavior}

Figure 6 shows the charge and discharge behavior of a 20-cell stack with $1 \mathrm{M}$ acid/base concentration at $25{ }^{\circ} \mathrm{C}$. Starting with OCV conditions, after $1 \mathrm{~min}$ a charge current density of $9 \mathrm{~mA} / \mathrm{cm}^{2}$ is imposed for $5 \mathrm{~min}$, followed by zero current for $1 \mathrm{~min}$ and a discharge current density of $9 \mathrm{~mA} / \mathrm{cm}^{2}$ for another $5 \mathrm{~min}$. The voltage measured across the stack (black line) is higher under charging and lower under discharging than the voltage measured with the Pt wire probes between all repeating cell units, because the electrode losses need to be added to the blue curve under charge and subtracted under discharge. The mean voltages measured along the $5 \mathrm{~min}$ charge and discharge periods are constant. Under constant acid and base concentrations, the measured voltages even remain constant during extended charge and discharge periods, indicating a stable operation. Again, the voltage measured across the second 5-cell package (V5cells_2nd, green dotted line) is lower than V5cells_1st (green solid line) at OCV as well as under charge/discharge, indicating the increased influence of the shunt currents in the stack center.

The absolute difference between the blue and the black curves should, however, be about equal for charge and discharge and vanish at OCV. This would be the case if the blue lines were shifted upwards by $0.7 \mathrm{~V}$, leading to an absolute difference between both curves at charge and discharge of about 3.4 V. This seems to be a reasonable estimate of the losses at the electrodes and across the electrode compartments during charge/discharge with $9 \mathrm{~mA} / \mathrm{cm}^{2}$, since under ideal conditions electrode losses of $2.07 \mathrm{~V}$ have been predicted by Table 1 . The required voltage shift of $0.7 \mathrm{~V}$ points to a measurement error of the Pt wire probes (blue curves). It is well known that measurements with Pt wire probes are less accurate than with Haber-Luggin electrodes as applied in [2]. In the summary of the measured results, presented in Figure 7, this voltage shift has been considered and compensated. 
20-cells stack with $1 \mathrm{M}$ acid/base at $9 \mathrm{~mA} / \mathrm{cm} 2$

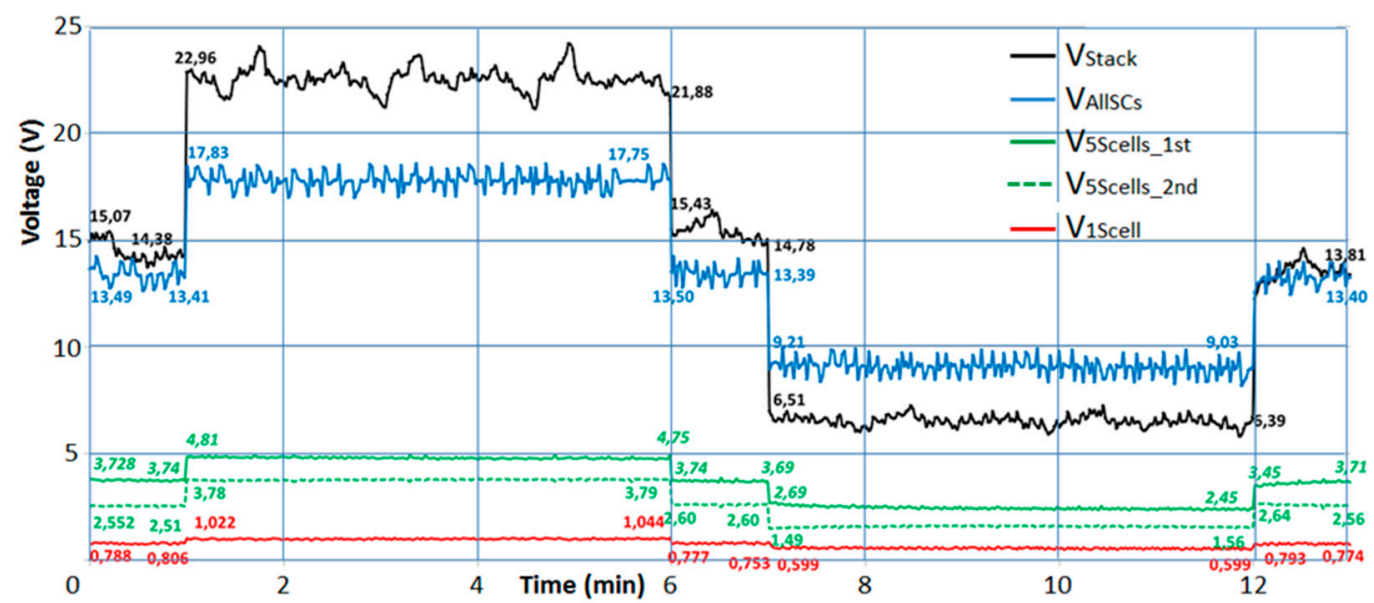

Figure 6. Charge and discharge behavior of a 20-cell stack with $1 \mathrm{M}$ acid/base at $25^{\circ} \mathrm{C}$ and $9 \mathrm{~mA} / \mathrm{cm}^{2}$ current density. The black line is the stack voltage measured across the electrodes; the blue line is the stack voltage across the 20-cell units. The voltages measured across the first repeating cell unit next to the electrode (red), the first 5-cell unit (green, solid) and the second 5-cell unit (green, dotted) are also shown.

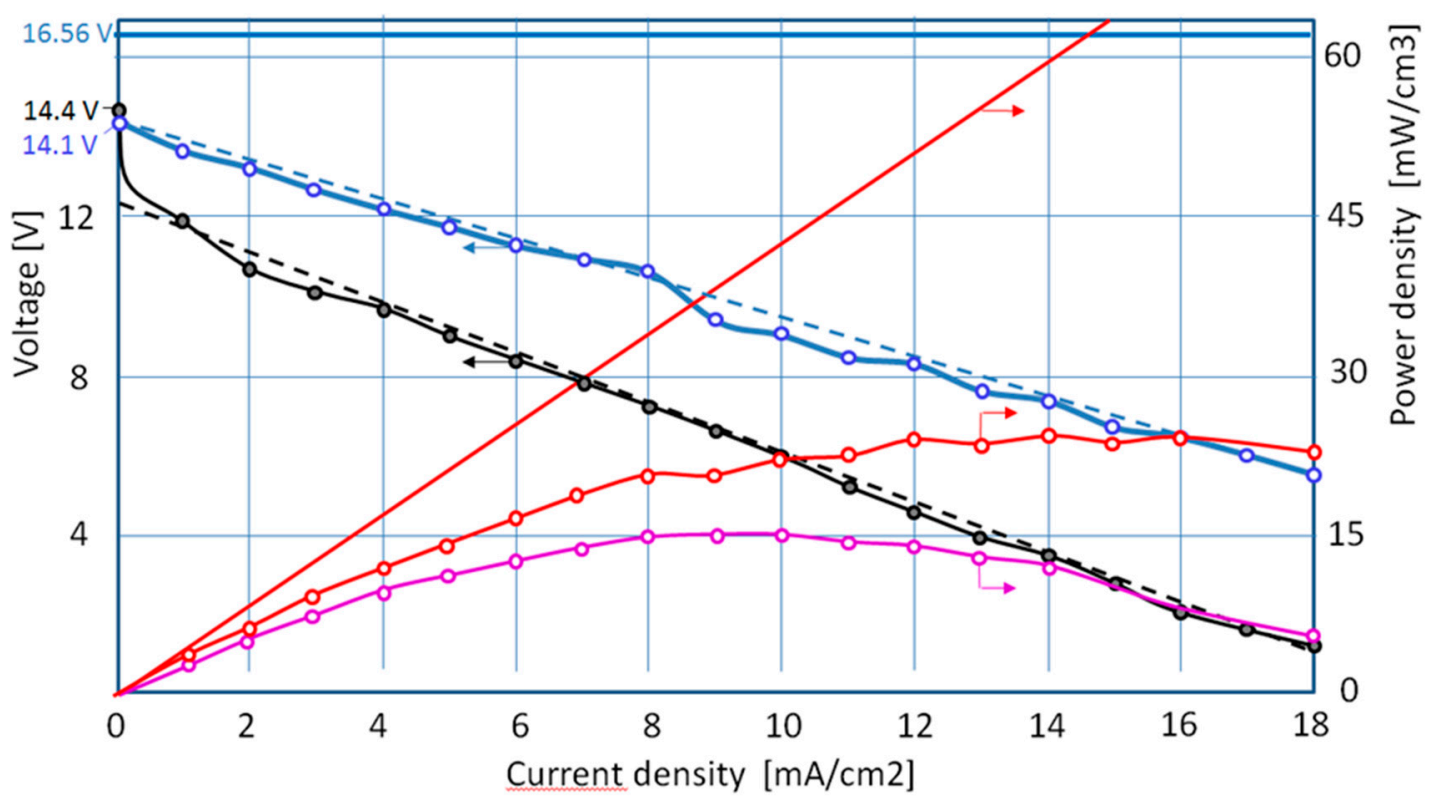

- ideal voltage of 20 cells $\rightarrow$ voltage measured across 20 cells $\multimap$ stack voltage $\quad$ ideal deal power density
$\multimap-$ power density of 20 cells stack, excluding electrode losses $\rightarrow-$ power density across stack (including electrode losses)

Figure 7. Discharge voltages and net discharge power densities of the 20-cell stack with $1 \mathrm{M}$ acid/base at $25{ }^{\circ} \mathrm{C}$, plotted over discharge current density.

In Figure 8, measured voltages are presented for increasing current densities under charge (increasing voltages) and under discharge (decreasing voltages). At each current density, the measurement continued until a stable voltage was established. Figure 8a shows the results of a 20-cell stack and Figure $8 \mathrm{~b}$ of a 15-cell stack, for $1 \mathrm{M}$ acid and base. Both results show the same general trends. The voltages measured across the electrodes of the whole stack are given by black dots and the measurements across all repeating cell units (excluding the electrodes) by blue dots. In addition, measurements across the first 5-cell unit (next to one electrode) are given by green solid 
lines and the measurements across the second 5-cell unit (in the middle of the stack) by green broken lines. Measurements for one repeating cell unit next to one electrode are displayed in red. If a shift of $+0.7 \mathrm{~V}$ is imposed on the blue curves, as discussed before, the electrode losses between charge and discharge are about equal. They increase moderately with increasing current density.
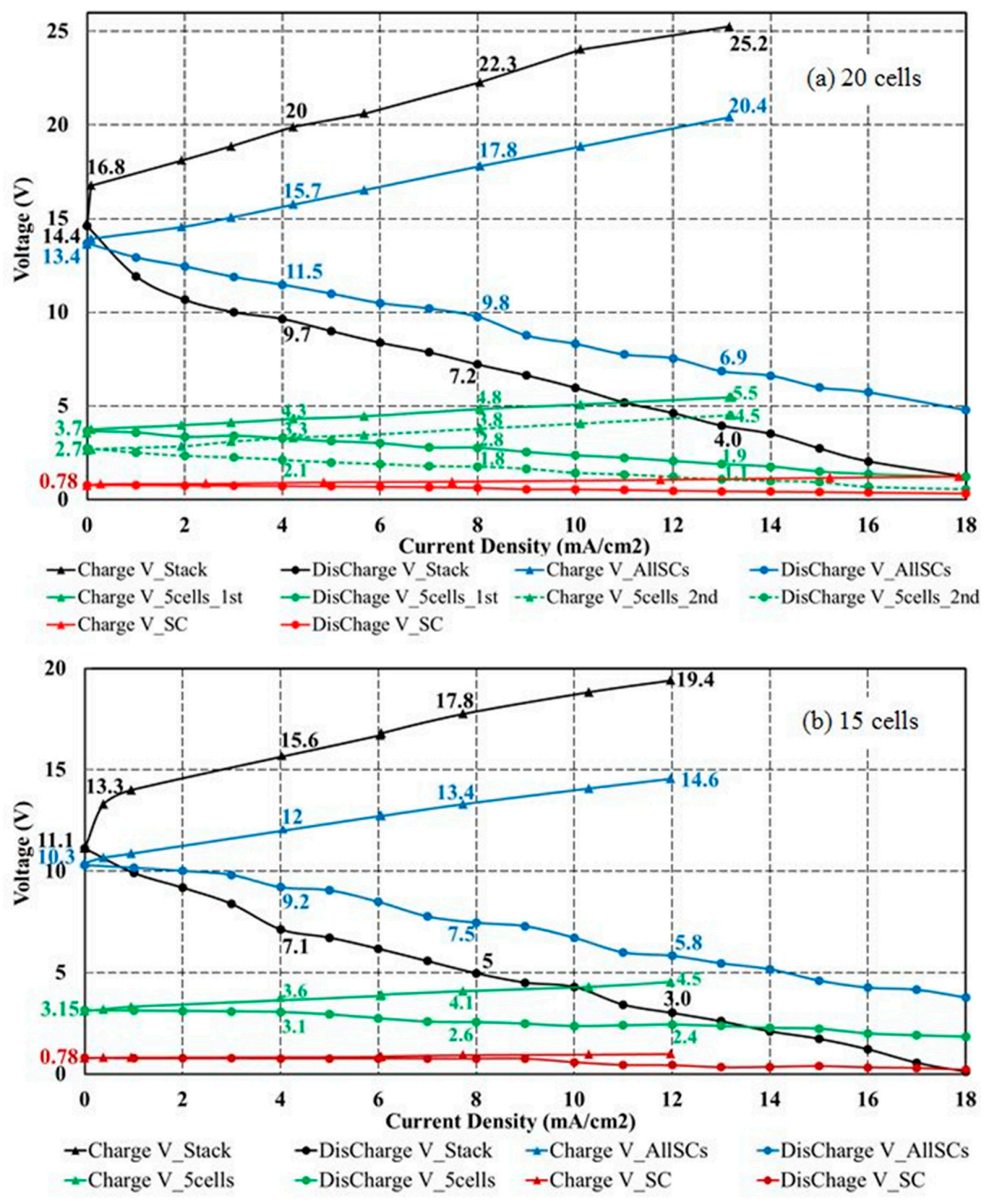

Figure 8. Current density measurements during charge and discharge with $1 \mathrm{M}$ acid and base at $25^{\circ} \mathrm{C}$ and $0.1 \mathrm{MPa}$ at steady state. Current-voltage curves of positive slope represent charging, of negative slope discharging. Results for a 20-cell stack are shown in (a) and for a 15-cell stack in (b). Displayed are the measured voltages, VSC (across BP (bipolar membranes) of the first single cell, red), V5cell_2nd (across the second 5-cell unit, green dotted), V5cell_1st (across the first 5-cell unit, green solid), VAllSCs (across all cell units measured between Pt electrodes, blue) and VStack (stack voltage between electrodes, black). 
A comparison of Figure 8a,b shows that the voltage losses increase with the number of unit cells. This is a consequence of the fact that the shunt current accumulates in the stack center, as discussed qualitatively with Figure 5. This shunt current has to be compensated by an increased neutralization reaction of $\mathrm{H}^{+}$and $\mathrm{OH}^{-}$in the bipolar membrane. The unit cells in the stack center therefore contribute less to the stack voltage if the cell number increases. A decrease of the voltage of the second 5-cell unit, located in the middle of the stack, compared to the first 5-cell voltage is also obvious in Figure 8a, demonstrating the influence of the increasing shunt current in the middle of the stack, both at charge and discharge.

\subsection{Discharge Power Density and Efficiency}

The focus of the present contribution is on the discharge behavior of flow batteries. Here, as in [2], power density PD, defined as net electric power, divided by stack volume, is useful for characterizing the discharge. For the stack volume, only the active area of the membranes and the thickness of each repeating cell unit $(1.96 \mathrm{~mm})$ have been considered, while the volume of both electrode chambers has not been included. In Figure 7, discharge voltage and net discharge power density of the tested 20-cell stack with $1 \mathrm{M}$ acid/base at $25^{\circ} \mathrm{C}$ are displayed over discharge current density. As explained in Section 3.3, the voltages measured across all single cells (the blue dotted line) have been moved up by $0.7 \mathrm{~V}$ (compared to Figure 8), to compensate for measurement errors of the Pt probes.

Considering an ideal behavior without losses across the stack (zero resistances) and with the theoretical single cell voltage of $0.828 \mathrm{~V}$, a constant voltage of $16.56 \mathrm{~V}$ would result, leading to a linear increase of power density over current density, marked by the solid red line. The actually measured voltages across all 20 cells of the stack over current density lead to the power densities as displayed by the red line with measurement bullets. The losses partly result from the Ohmic resistances across the membranes and the electrolyte compartments, as already considered in the single-cell experiments in [2]. Another part results from the shunt currents, discussed in Section 3.2.

If we include the measured voltage drop over the electrodes, the pink line with bullets results in the measured power density of the stack. The difference between the red and the pink line is attributed to additional losses in the electrode compartments. The fact that the total losses are substantially higher than predicted from the single-cell experiments can be attributed to the shunt currents through the feed/exit lines. In addition, a nonuniform flow distribution of the electrolytes through adjacent cells could have contributed. This can be concluded from differences between measured voltages of adjacent cell units.

The highest power density for the 20-cell stack of $15 \mathrm{~mW} / \mathrm{cm}^{3}$ has been reached at $10 \mathrm{~mA} / \mathrm{cm}^{2}$, corresponding to a stack power output of $6 \mathrm{~W}$ with $36 \%$ voltage efficiency. Neglecting the electrode chamber losses, the highest stack power goes up to $9 \mathrm{~W}$ or $24 \mathrm{~mW} / \mathrm{cm}^{-3}$ with $50 \%$ voltage efficiency.

The power density decreases at higher current densities due to increasing resistive losses. As observed in the single-cell experiments [2], discharge current densities well above $20 \mathrm{~mA} / \mathrm{cm}^{2}$ resulted in unstable behavior, with voltage breakdown due to water accumulation inside BP. However, this is above the discharge power densities reached in the stack experiments.

\section{Conclusions}

The experimental results obtained in this study show that the single cell results presented in [2] can be extrapolated to multicell stacks, but additional losses have to be considered. Most importantly, the influence of shunt currents has to be taken into account. As demonstrated with open current experiments under self-discharging conditions in Section 3.2, the influence of shunt currents through the parallel acid/base feed/exit lines increases with increasing number of cell units. It is most pronounced in the middle of the stack, where it can substantially reduce the open cell voltage.

The single cell experiments reported in [2] showed that at higher acid/base concentrations, a breakdown of the discharge voltage occurred, if the current density was raised above a certain value between 20 and $40 \mathrm{~mA} / \mathrm{cm}^{2}$. This was attributed to a delamination of the bipolar membrane, caused by 
the excessive formation of water through the neutralization reaction of $\mathrm{H}^{+}$and $\mathrm{OH}^{-}$in the reaction layer. However, these current densities were well above the discharge current densities reached in the stack experiments of Figures 6 and 8. Delamination of bipolar membranes during discharge was not observed in the stack results presented.

Figure 7 summarizes the experimental discharge results for the 20-cell stacks and points to possibilities for improvement. A reduction of the influence of shunt currents would directly reduce the difference between the (ideal) red solid line and the measured red dotted line. A straightforward approach would be to change the acid and base flow pattern from parallel to a serial flow, where all of the acid and base flows consecutively upwards in one and downwards in the next acid/base chamber. Then, minor shunt currents could only occur between adjacent cells, driven by the single cell voltages but not by the total stack voltage, as in case of the parallel feed/exit lines. Preliminary experiments at open current under self-discharge (similar to Figure 4) proved that the self-discharge of a 5-cell stack with serial flow of acid and base was considerably slower, compared with a similar stack with parallel flow. However, for the present design the pressure drop across the acid/base feed/exit lines was substantially increased. This would result in an unacceptable pressure drop for a 20-cell stack with serial flow.

Since Figure 4 has shown that a 5-cell stack with parallel flow was only marginally affected by shunt currents, a combination of parallel and serial flow could be a compromise between pressure drop and shunt current. The parallel flow through the acid and base compartments should change direction after, for example, every 5 to 10 cells. Electrode losses (the difference between the red and the pink lines in Figure 7) could be reduced, e.g., by improved, gas-consuming electrodes [13].

With respect to higher power densities, the positive influence of larger concentrations of the electrolytes has to be balanced against reduced permselectivities of the ion exchange membranes used. Here, the challenge is to develop monopolar and bipolar membranes with increased fixed-charge concentrations as already discussed in [2]. In the single-cell experiments [2], water accumulation at the BP interface resulted in a breakdown of the cell voltage at current densities above about $30 \mathrm{~mA} / \mathrm{cm}^{2}$ for $1 \mathrm{M}$ acid/base. This was well above the current densities reached in the stack experiments. Nevertheless, an improved water transport through BP will be a further challenge for BP membranes optimized for REDBP.

Author Contributions: Conceptualization, G.E., H.S. and U.N.; formal analysis, J.X.; investigation, J.X.; methodology, J.X. and H.S.; resources, J.X. and H.S.; supervision, G.E., H.S. and U.N. All authors have read and agreed to the published version of the manuscript.

Funding: Jiabing Xia gratefully acknowledges the Ph.D. scholarship from the GREES program at University of Stuttgart in Germany.

Conflicts of Interest: The authors declare no conflict of interest.

\section{List of Abbreviations}

$\begin{array}{ll}\text { AM } & \text { anion exchange membrane } \\ \text { BM } & \text { bipolar membrane } \\ \text { CM } & \text { cation exchange membrane } \\ \text { OCV } & \text { open circuit voltage } \\ \text { REDBP } & \text { reverse electrodialysis with bipolar membranes }\end{array}$

\section{References}

1. Post, J.W.; Veerman, J.; Hamelers, H.V.M.; Euverink, G.J.W.; Metz, S.J.; Nymeijer, K.; Buisman, C.J.N. Salinity-gradient power: Evaluation of pressure retarded osmosis and reverse electrodialysis. J. Membr. Sci. 2007, 288, 218-230. [CrossRef]

2. Xia, J.; Eigenberger, G.; Strathmann, H.; Nieken, U. Flow battery based on reverse electrodialysis with bipolar membranes: Single cell experiments. J. Membr. Sci. 2018, 565, 157-168. [CrossRef] 
3. Walther, J.F. Process for Production of Electrical Energy from the Neutralization of Acid and Base in a Bipolar Membrane Cell. U.S. Patent 06183483, 19 January 1982.

4. Zholkovskij, E.; Müller, M.; Staude, E. The storage battery with bipolar membranes. J. Membr. Sci. 1998, 141, 231-243. [CrossRef]

5. Pretz, J.; Staude, E. Reverse electrodialysis (RED) with bipolar membranes, an energy storage system. Phys. Chem. 1998, 102, 676-685. [CrossRef]

6. Huang, C.; Xu, T. Electrodialysis with bipolar membranes for sustainable development. Environ. Sci. Technol. 2006, 40, 5233-5243. [CrossRef] [PubMed]

7. Parasuraman, A.; Lim, T.; Menictas, C.; Skyllas-Kazacos, M. Review of material research and development for vanadium redox flow battery applications. Electrochim. Acta 2013, 101, 27-40. [CrossRef]

8. Xia, J. Reverse Electrodialysis with Bipolar Membranes (REBP) as an Energy Storage System. Ph.D. Thesis, Fakultät Verfahrenstechnik of Stuttgart University, Stuttgart, Germany, 10 August 2018.

9. Fumatech, Home Page. Available online: www.fumatech.com (accessed on 10 January 2020).

10. Yin, C.; Guo, S.; Fang, H.; Liu, J.; Li, Y.; Tang, H. Numerical and experimental studies of stack shunt current for vanadium redox flow battery. Appl. Energy 2015, 151, 237-248. [CrossRef]

11. Fink, H.; Remy, M. Shunt currents in vanadium flow batteries: Measurement, modelling and implications for efficiency. J. Power Sources 2015, 284, 547-553. [CrossRef]

12. Ye, Q.; Hu, J.; Cheng, P.; Ma, Z. Design trade-offs among shunt current, pumping loss and compactness in the piping system of a multi-stack vanadium flow battery. J. Power Sources 2015, 296, 352-364. [CrossRef]

13. Kintrup, J.; Millaruelo, M.; Trieu, V.; Bulan, A.; Mojica, E.S. Gas Diffusion Electrodes for Efficient Manufacturing of Chlorine and Other Chemicals. Electrochem. Soc. 2018, 26, 73-76. [CrossRef]

(C) 2020 by the authors. Licensee MDPI, Basel, Switzerland. This article is an open access article distributed under the terms and conditions of the Creative Commons Attribution (CC BY) license (http://creativecommons.org/licenses/by/4.0/). 